\title{
Article \\ Modular Combined DC-DC Autotransformer for Offshore Wind Power Integration with DC Collection
}

\author{
Yuanjian Song, Zheren Zhang * and Zheng Xu (1) \\ Department of Electrical Engineering, Zhejiang University, Hangzhou 310058, China; \\ yuanjiansong18@163.com (Y.S.); xuzheng007@zju.edu.cn (Z.X.) \\ * Correspondence: 3071001296zhang@zju.edu.cn
}

\begin{abstract}
Offshore wind farms (OWFs) integration are attractive extensively for furnishing more robust power than land wind farms. This paper introduces a modular combined DC-DC autotransformer (MCAT), which contributes to the offshore wind power integration of DC grids with different voltage levels. Traditional DC transformers contains medium- or high-frequency converter transformers, which have the disadvantages of high manufacturing difficulty and cost. These shortcomings seriously affect the progress of commercial application of DC transformers. To solve these problems, in the proposed MCAT, converter transformers are replaced with a DC-isolation capacitor and a compensation inductor in series to reduce the footprint of offshore platforms and improve economy. Theoretical analysis is carried out for the MCAT operation principle. Selection methods of main circuit parameters for the MCAT are discussed in detail. Then, corresponding control strategies of the MCAT are proposed. Finally, the effectiveness of the proposed MCAT and its control strategies are validated by time domain simulations in PSCAD/EMTDC. The time-domain simulation results show the correctness of the main circuit parameters and the rationality of the MCAT control strategies.
\end{abstract}

Keywords: offshore wind farm (OWF); DC collection grid; modular combined DC-DC autotransformer (MCAT); DC-isolation capacitor; compensation inductor

Citation: Song, Y.; Zhang, Z.; Xu, Z. Modular Combined DC-DC

Autotransformer for Offshore Wind Power Integration with DC

Collection. Appl. Sci. 2022, 12, 1810. https://doi.org/10.3390/app12041810

Academic Editor: Giovanni Petrone

Received: 22 November 2021

Accepted: 8 February 2022

Published: 10 February 2022

Publisher's Note: MDPI stays neutral with regard to jurisdictional claims in published maps and institutional affiliations.

Copyright: (c) 2022 by the authors. Licensee MDPI, Basel, Switzerland. This article is an open access article distributed under the terms and conditions of the Creative Commons Attribution (CC BY) license (https:// creativecommons.org/licenses/by/ $4.0 /)$.

\section{Introduction}

Offshore wind energy has drawn wide interest due to its distinctive advantages, such as rich wind resources, high utilization hours, and no need to occupy land resources [1]. Recently, China has proposed to build new power systems dominated by renewable energy, which facilitates the rapid development of offshore wind farms (OWFs).

The high voltage direct current (HVDC) transmission system is preferred to the traditional AC transmission system for the grid integration of large-scale OWFs. In the conventional HVDC transmission system for OWFs, wind turbines (WTs) are integrated together with an AC collection grid and then connected to an offshore substation containing a step-up transformer and a rectifier [2]. However, OWFs based on AC collection grids need lots of AC cables, bulky step-up transformers, and large expensive offshore platforms. To address this problem, OWFs based on DC collection grids are researched broadly $[3,4]$. In DC-collection-grids OWFs, WTs are interconnected with DC cables and connected to DC-DC converters, and the low DC voltage is raised to the HVDC transmission voltage. Compared with AC-collection-grids OWFs, DC-collection-grids OWFs could reduce the footprint requirement and get the higher power transmission efficiency $[5,6]$.

According to interconnection schemes of WTs, DC-collection-grids OWFs are classified into DC parallel-connection and DC series-connection schemes [7], as shown in Figure 1. In the series-connection scheme, WTs at two ends have to withstand a high DC voltage. In addition, lots of WTs will be bypassed when unexpected faults happen. If the DC voltage of the OWF falls below the threshold limit, the entire OWF will be shut down undesirably [8]. These defects definitely limit the application of DC series-connection scheme. Therefore, the DC parallel-connection scheme is adopted in this paper. 


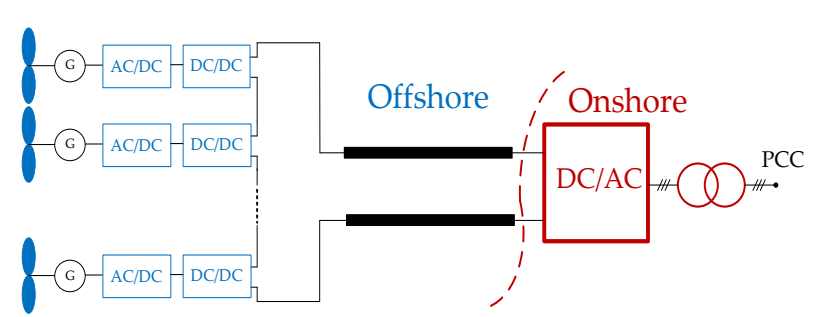

(a)

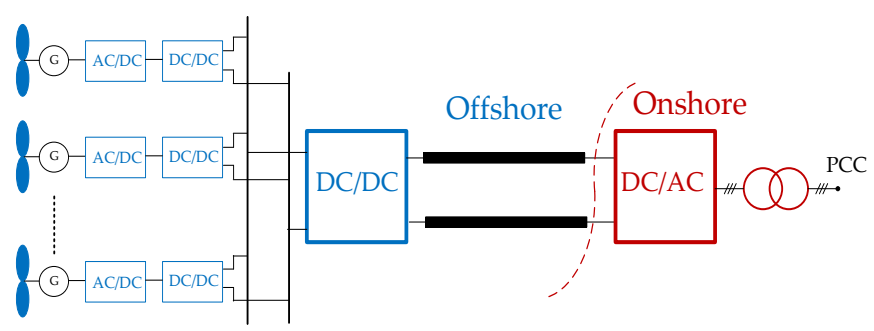

(b)

Figure 1. DC collection grids of OWF: (a) DC series-connection OWF; (b) DC parallel-connection OWF.

The DC parallel-connection scheme is as shown in Figure 1b. An internal DC-DC converter inside the WT boosts the low DC output voltage of AC-DC converters to the medium voltage (MV) [9]. Several WTs are connected in parallel forming an MVDC grid. Then the MV is stepped up to the high voltage (HV) by a central offshore DC-DC converter. In other words, the DC output voltage of a WT needs two-stage step-up. This two-stage step-up method allows the ratio of DC-DC converters not too large to design, and also enhances the fault-ride-through ability of the wind farm [10]. Conclusively, the DC parallelconnection scheme with the DC voltage two-stage step-up is more suitable for the OWF integration currently.

According to the classification criteria of galvanic isolation, DC-DC converters for HVDC are divided into isolated topologies and non-isolated topologies. With the help of the $\mathrm{AC}$ transformers, isolated topologies could achieve the requirement of the high stepping ratio and galvanic isolation, but they show characteristics of high cost and large operation losses. Non-isolated topologies require less power semiconductor devices and no need for a transformer or the transformer which does not have to be rated for the full power of the DC-DC converter [11]. Compared with isolated topologies, non-isolated topologies have a smaller footprint and less operation losses and reduce the footprint of an offshore platform which is the major part of the total cost in an OWF [12]. So non-isolated DC-DC converters are preferred to isolated DC-DC converters for OWFs based on HVDC transmission.

The primary classification of non-isolated topologies is made based on the presence of transformers, and they are divided into DC autotransformer converters and transformerless converters. [13] proposed a transformerless converter with resonant topologies. Its principle is to use the resonance as a step-up mechanism while achieving the soft switching of semiconductors at the same time. The main disadvantage of these topologies is that it is difficult to balance the sharing of currents or voltages in semiconductor devices and achieve large power transmission. Obviously, resonant topologies are not suitable for scenario where large power transmission is required, such as OWFs. A step-up unidirectional DC-DC autotransformer is briefly introduced in [14], but the footprint of this topology is still very large due to the application of converter transformers. An input-independentoutput-series structure is proposed in [15] with inter-module power balancing units. A nonisolated modular DC-DC auto-transformer (MDCAT) is proposed in [16], the developed two-port submodules are connected in the input-series-output-series structure. However, the topology and control strategies of this MDCAT are complex.

Converter transformers cause extra power loss and increased cost. Aiming at improving operation efficiency and reducing the cost, this paper proposes a modular-combined DC-DC autotransformer (MCAT). In the MCAT, converter transformers are replaced by a DC-isolated capacitor and a compensation inductor in series, which are much smaller in size and cost than transformers, and do not incur additional power losses in series resonance.

The reminder of this paper is organized as follows. Section 2 describes the circuit configuration of the proposed MCAT. The selection methods of main circuit parameters for the MCAT are introduced in Section 3. Section 4 analyzes the corresponding control strategy under steady-state operation and the AC side short circuit fault recovery strategy. 
In addition, the recovery strategy of the internal three-phase short-circuit fault is proposed. To validate the feasibility and effectiveness of the proposed MCAT and control strategies, the simulation studies in PSCAD/EMTDC are presented in Section 5. Finally, Section 6 concludes this paper.

\section{MCAT Topology and Its Operation Principles}

\subsection{Topological Structure}

As depicted in Figure 2, two DC grids with different DC voltage levels are connected by the proposed MCAT. MMCs highlighted by blue and red colors are defined as a low voltage module (LVM) and a high voltage module (HVM), respectively. The LVM is composed of $M$ identical MMCs including $\mathrm{MMC}_{\mathrm{L}, 1}$ to $\mathrm{MMC}_{\mathrm{L}, \mathrm{M}}$. Likewise, the $\mathrm{HVM}$ is composed of $2 \mathrm{~N}$ identical MMCs including $\mathrm{MMC}_{\mathrm{H}, 1}$ to $\mathrm{MMC}_{\mathrm{H}, 2 N}$. It is obvious that $M$ and $N$ are driven by voltage levels of DC grids on two sides of the MCAT.

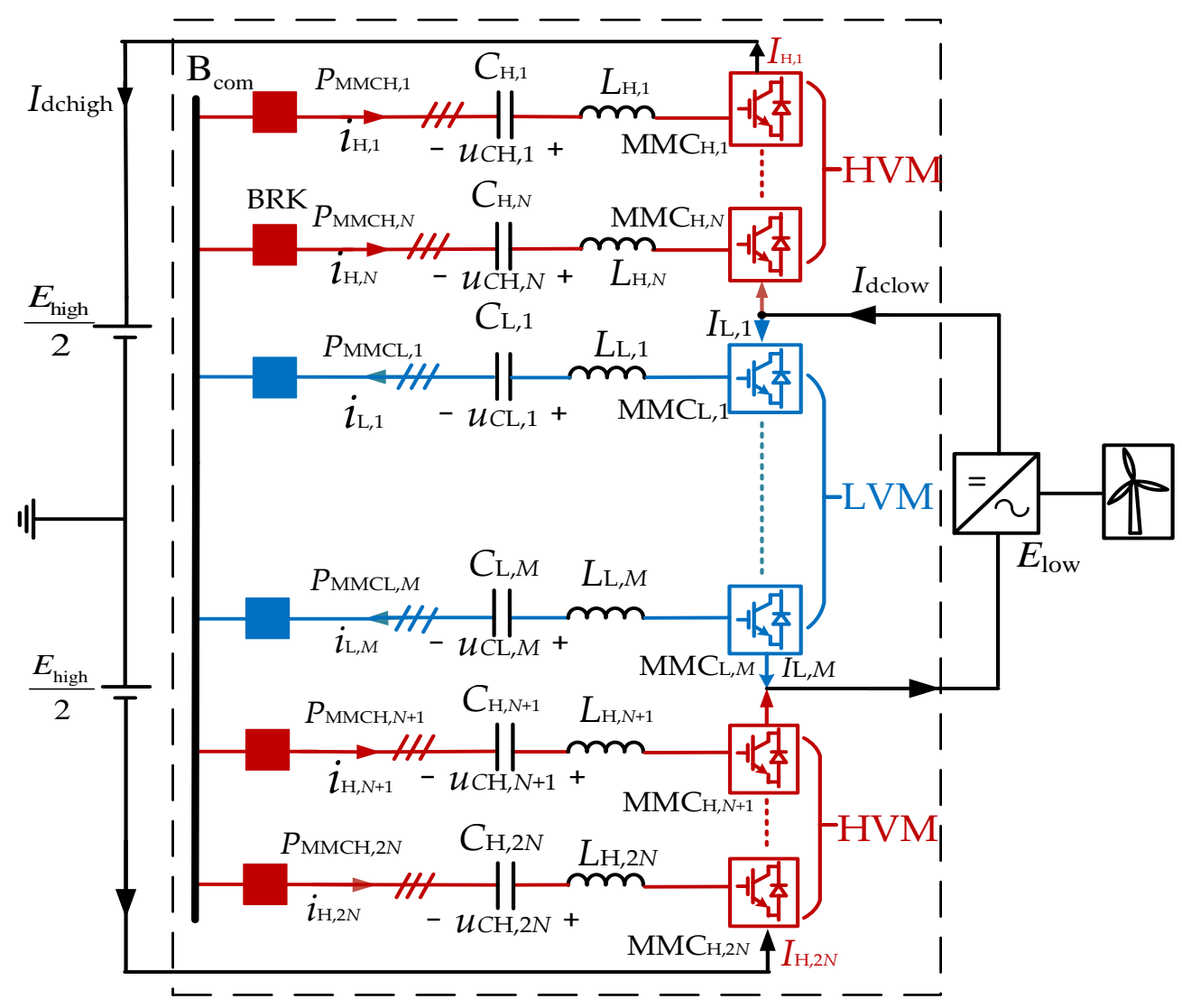

Figure 2. Schematic diagram of the MCAT topology.

The function of converter transformers is mainly focused on three aspects [17]:

(1) Coordinating the AC system voltage and the AC output voltage of MMC.

(2) Galvanic separation between the AC system and the MMC to eliminate the DC offset voltage.

(3) Acting as the inductor to smooth the current and suppress the fault current.

According to the operation principle of the MCAT, the item (2) is an indispensable function. This paper uses a capacitor (namely DC-isolation capacitor) to withstand the DC offset voltage, so that the converter transformer is eliminated. Since the introduced DC-isolation capacitor would produce reactive power, an inductor (namely compensation inductor) is installed to compensate the reactive power and improve the MCAT operation efficiency. In order to reduce the footprint of DC-isolation capacitors and compensation inductors, the medium frequency $(100 \mathrm{~Hz} 400 \mathrm{~Hz})$ is applied at the MCAT AC side. AC circuit breakers are also equipped for isolating the $\mathrm{AC}$ fault. 


\subsection{Operation Principles of the MCAT}

Neglecting transmission losses, the rated DC power $P_{N}$ transmitted from the highvoltage DC grid to the low-voltage one is described as:

$$
P_{\mathrm{N}}=E_{\text {high }} I_{\mathrm{dchigh}}=E_{\mathrm{low}} I_{\mathrm{dclow}}
$$

where $E_{\text {high }}$ and $E_{\text {low }}$ are DC voltages of high-voltage and low-voltage DC grids, respectively $\left(E_{\text {high }}>E_{\text {low }}\right) ; I_{\text {dchigh }}$ and $I_{\text {dclow }}$ are DC currents of high-voltage and low-voltage DC grids, respectively. The positive direction of currents and voltages are shown in Figure 2, and the DC voltage ratio $k_{\mathrm{dc}}\left(k_{\mathrm{dc}}>1\right)$ is defined as:

$$
k_{\mathrm{dc}}=\frac{E_{\text {high }}}{E_{\text {low }}}
$$

The transmission power of each MMC in HVM and LVM is described as:

$$
\left\{\begin{array}{l}
P_{\mathrm{MMCH}, n}=\frac{\left(E_{\mathrm{high}}-E_{\text {low }}\right) I_{\mathrm{dchigh}}}{2 N}=\frac{P_{\mathrm{N}}}{2 N}\left(1-\frac{1}{k_{\mathrm{dc}}}\right) \\
P_{\mathrm{MMCL}, m}=\frac{E_{\mathrm{low}}\left(I_{\mathrm{dclow}}-I_{\mathrm{dchigh}}\right)}{M}=\frac{P_{\mathrm{N}}}{M}\left(1-\frac{1}{k_{\mathrm{dc}}}\right)
\end{array}\right.
$$

where $P_{\mathrm{MMCH}, n}$ and $P_{\mathrm{MMCL}, m}$ are the transmission power of the $n$th MMC in HVM and the $m$ th MMC in LVM, respectively $(n=1,2, \ldots, 2 N, m=1,2, \ldots, M)$.

$P_{\mathrm{N}}$ is transmitted through two different paths. One path is HVM-AC bus-LVM, this part of $P_{\mathrm{N}}$ is delivered through the DC-AC-DC conversion and named $P_{\mathrm{dc}-\mathrm{ac}-\mathrm{dc}}$. The other part of $P_{\mathrm{N}}$ flows from the high-voltage DC grid to the low-voltage DC grid directly and is named $P_{\text {dir }} . P_{\mathrm{dc}-\mathrm{ac}-\mathrm{dc}}$ and $P_{\mathrm{dir}}$ are calculated as (4) and (5):

$$
\begin{gathered}
P_{\mathrm{dc}-\mathrm{ac}-\mathrm{dc}}=\sum_{m=1}^{M} P_{\mathrm{MMCL}, m}=\sum_{n=1}^{2 N} P_{\mathrm{MMCH}, n}=P_{\mathrm{N}}\left(1-\frac{1}{k_{\mathrm{dc}}}\right) \\
P_{\mathrm{dir}}=E_{\mathrm{low}} I_{\mathrm{dchigh}}=E_{\mathrm{low}} \frac{P_{\mathrm{N}}}{E_{\mathrm{high}}}=\frac{P_{\mathrm{N}}}{k_{\mathrm{dc}}}
\end{gathered}
$$

$P_{\text {MCAT }}$ is the total capacity of the MCAT and is calculated as (6):

$$
P_{\mathrm{MCAT}}=\sum_{m=1}^{M} P_{\mathrm{MMCL}, m}+\sum_{n=1}^{2 N} P_{\mathrm{MMCH}, n}=2 P_{\mathrm{N}}\left(1-\frac{1}{k_{\mathrm{dc}}}\right)
$$

Comparing (6) with (5), $P_{\mathrm{MCAT}}$ depends only on $P_{\mathrm{dc}-\mathrm{ac}-\mathrm{dc}}$

\section{MCAT Main Circuit Parameters Selection}

MCAT main circuit parameters consist of MMC main circuit parameters, DC-isolation capacitors, and compensation inductors. As the selection methods of MMC main circuit parameters (e.g., sub-module capacitors, arm inductors, etc.,) have been discussed particularly in [18], this section only focuses on DC-isolation capacitors and compensation inductors. For the sake of clarity of this section, Table A1 with explanations of the abbreviations and symbols used in this section are provided in Appendix A.

The voltage $u_{\mathrm{cj}}$ of $C_{j}(j=1,2, \ldots, M+2 N)$ is always composed of the DC offset voltage $U_{\mathrm{vdcj}}$ and the AC voltage $\Delta u_{\mathrm{cj}}$, which is expressed as:

$$
u_{\mathrm{c} j}=U_{\mathrm{vdc} j}+\Delta u_{\mathrm{c} j}
$$

$U_{\mathrm{vdcj}}$ is supposed to be eliminated by the DC-isolation capacitor. The degree of $\Delta u_{\mathrm{cj}}$ fluctuations could affect the stability of the AC side. In this regard, the value of capacitors should be taken as large as possible to reduce the $\Delta u_{\mathrm{c} j}$ fluctuations. On the other hand, DC-isolation capacitors need to be charged by the connected MMCs in the start or 
fault recovery process of MCAT and excessive value would slow down the charging rate. Therefore, DC-isolation capacitors need to be selected by considering the above two factors.

Ignoring the power losses in steady-state operation, the active power $P_{\mathrm{MMC} j}$ and the reactive power $Q_{\mathrm{MMC}}$ transmitted by the $\mathrm{MMC}_{j}$ could be described as:

$$
\left\{\begin{array}{l}
P_{\mathrm{MMC} j}=\sqrt{3} U_{\mathrm{vacj}} I_{j} \cos \delta_{j} \\
Q_{\mathrm{MMC} j}=\sqrt{3} U_{\mathrm{vacj}} I_{j} \sin \delta_{j}
\end{array}\right.
$$

where $U_{\text {vacj }}$ is the fundamental RMS (root mean square) L-L (line-line) voltage at $\mathrm{MMC}_{j}$ valve side, $I_{j}$ is the fundamental RMS line current at $\mathrm{MMC}_{j}$ valve side, and $\delta_{j}$ is the phase angle between $U_{\mathrm{vacj}}$ and $I_{j}$. In the steady-state condition, $U_{\mathrm{vac}}, I$, and $\delta$ of each MMC are similar. Furthermore, if $\mathrm{MMC}_{j}$ adopts reactive power control with the reference value $0 \mathrm{pu}$, $Q_{\mathrm{MMC} j}$ will be controlled to $0, U_{\text {vacj }}$ and $I_{j}$ will be in the same phase $\left(\delta_{j}=0\right)$. Considering $\delta_{j}=0$ and ignoring high-order harmonics, $\Delta U_{\mathrm{cj}}$ is described as:

$$
\Delta U_{\mathrm{c} j}=\frac{I_{j}}{\omega C_{j}}=\frac{P_{\mathrm{MMC} j}}{\sqrt{3} U_{\mathrm{vac} j}} \frac{1}{2 \pi f C_{j}}
$$

where $\Delta U_{\mathrm{cj}}$ is the fundamental RMS voltage of $\Delta u_{\mathrm{cj}}, f$ is the fundamental frequency at the MCAT AC side. The voltage fluctuation rate $\alpha_{j}$ of $C_{j}$ is defined as:

$$
\alpha_{j}=\frac{\sqrt{2} \Delta U_{\mathrm{c} j}}{U_{\mathrm{vdc} j}} \times 100 \%
$$

where, $\alpha_{j}$ is the fluctuation ratio of $u_{\mathrm{c} j}$, and it should be limited within $25 \%$ according to engineering experience in [19].

In (9) and (10), $U_{\text {vac }}$ of each MMC and $f$ in the MCAT are similar under the steady-state operation, but $U_{\mathrm{vdc}}$ and $P_{\mathrm{MMC}}$ of the LVM are different from those of the HVM. As a result, parameters of DC-isolation capacitors $C$ and compensation inductors $L$ in HVM and LVM are supposed to be calculated respectively.

\subsection{Parameter Calculation of DC-Isolation Capacitors and Compensation Inductors in HVM}

In the HVM, $\Delta U_{\mathrm{c}}$ of each DC-isolation capacitor is almost identical because every DC-isolation capacitor has the same value, and the $U_{\mathrm{vdc}}$ of $\mathrm{MMC}_{\mathrm{H}, \mathrm{N}}$ (and $\mathrm{MMC}_{\mathrm{H}, \mathrm{N}+1}$ ) is lowest in the HVM. According to (10), $\alpha_{\mathrm{H}, \mathrm{N}}\left(\right.$ or $\left.\alpha_{\mathrm{H}, N+1}\right)$ is largest in the HVM and supposed to be calculated particularly. $U_{\mathrm{vacH}, \mathrm{N}}, U_{\mathrm{vdcH}, \mathrm{N}}$ and $P_{\mathrm{MMCH}, \mathrm{N}}$ are described as [11]:

$$
\begin{gathered}
u_{\mathrm{vH}, N}=u_{\mathrm{vacH}, N}+U_{\mathrm{vdcH}, N} \\
U_{\mathrm{vacH}, N}=1.05 \frac{U_{\mathrm{dcH}, N}}{2} \\
U_{\mathrm{vdcH}, N}=\frac{\left(E_{\mathrm{low}}+U_{\mathrm{dcH}, N}\right)}{2} \\
P_{\mathrm{MMCH}, \mathrm{N}}=\frac{P_{\mathrm{N}}\left(1-1 / k_{\mathrm{dc}}\right)}{2 N}
\end{gathered}
$$

where $u_{\mathrm{vH}, N}$ is the voltage at $\mathrm{MMC}_{\mathrm{H}, \mathrm{N}}$ valve side, $u_{\mathrm{vacH}, \mathrm{N}}$ and $U_{\mathrm{vdcH}, \mathrm{N}}$ are the AC component and DC component of $u_{\mathrm{vH}, N} \cdot U_{\mathrm{vacH}, N}$ are the fundamental RMS L-L voltage at $\mathrm{MMC}_{\mathrm{H}, \mathrm{N}}$ valve side, $U_{\mathrm{dcH}, \mathrm{N}}$ is the $\mathrm{DC}$ voltage of $\mathrm{MMC}_{\mathrm{H}, \mathrm{N}}$. Substituting these variables into Equation (10), $C_{\mathrm{H}, N}$ is expressed as follows:

$$
\begin{aligned}
C_{\mathrm{H}, N} & =\frac{\sqrt{2}\left(1-1 / k_{\mathrm{dc}}\right) P_{\mathrm{N}} / 2 \mathrm{~N}}{\sqrt{3} \times \frac{1.05}{2} U_{\mathrm{dcH}, \mathrm{N}} 2 \pi f C_{\mathrm{H}, N}} \frac{1}{\frac{\left(u_{\mathrm{dcH}, N}+E_{\mathrm{low}}\right)}{2}} \\
& =0.248 \frac{\left(1-1 / k_{\mathrm{dc}}\right) P_{\mathrm{N}}}{N f \alpha_{\mathrm{H}, N} U_{\mathrm{dcH}, N}\left(U_{\mathrm{dcH}, N}+E_{\mathrm{low}}\right)}
\end{aligned}
$$


where $\alpha_{\mathrm{H}, \mathrm{N}}$ denotes the rate of fluctuation of $u_{\mathrm{CH}, \mathrm{N}} . \alpha_{\mathrm{H}, \mathrm{N}}$ is an artificial technical index. After specifying $\alpha_{\mathrm{H}, N}$, the corresponding value of $C_{\mathrm{H}, N}$ could be calculated by (15). The DC-isolation capacitor and the compensation inductor are supposed to occur in series resonance at $f$ so that they produce no reactive power. For this purpose, the calculation expression of $L_{\mathrm{H}, \mathrm{N}}$ is:

$$
L_{\mathrm{H}, N}=\frac{1}{(2 \pi f)^{2} C_{\mathrm{H}, N}}
$$

After obtaining the values of $C_{\mathrm{H}, N}$ and $L_{\mathrm{H}, \mathrm{N}}$, the value of other DC-isolation capacitors in the HVM could be taken as the $C_{\mathrm{H}, \mathrm{N}}$, so that their $\alpha$ are smaller than $\alpha_{\mathrm{H}, \mathrm{N}}$ and $\alpha_{\mathrm{H},(\mathrm{N}+1)}$, as mentioned above. The values of other DC-isolation capacitors and compensation inductors in the HVM are described as:

$$
\left\{\begin{array}{l}
C_{\mathrm{H}, 1}=\cdots=C_{\mathrm{H}, N}=\cdots=C_{\mathrm{H}, 2 N} \\
L_{\mathrm{H}, 1}=\cdots=L_{\mathrm{H}, N}=\cdots=L_{\mathrm{H}, 2 N}
\end{array}\right.
$$

\subsection{Parameter Calculation of DC-Isolation Capacitors and Compensation Inductors in LVM}

In the LVM, the calculation of DC-isolation capacitors and compensation inductors depend on $M$, which is discussed as follows:

(1) When $M=1$, the DC-isolation capacitors and compensation inductors are excluded from the LVM.

(2) When $M=2,4,6, \ldots, \mathrm{MMC}_{\mathrm{L}, M / 2}$ (and $\mathrm{MMC}_{\mathrm{L},(M / 2)+1}$ ) has the lowest DC offset voltage in the $\mathrm{LVM}$, and $\alpha_{\mathrm{L}, M / 2}$ (and $\alpha_{\mathrm{L},(M / 2)+1}$ ) is largest correspondingly.

(3) When $M=3,5,7, \ldots, \mathrm{MMC}_{\mathrm{L},(M-1) / 2}$ (and $\mathrm{MMC}_{\mathrm{L},(M+3) / 2)}$ has the lowest $\mathrm{DC}$ offset voltage, and $\alpha_{\mathrm{L},(M-1) / 2}$ (and $\left.\alpha_{\mathrm{L},(M+3) / 2}\right)$ is largest correspondingly.

Take case (2) as an example to calculate DC-isolation capacitors and compensation inductors. $U_{\mathrm{vacL}, M / 2}, U_{\mathrm{vdcL}, M / 2}$, and $P_{\mathrm{MMCL}, M / 2}$ are expressed as [17]:

$$
\begin{gathered}
u_{\mathrm{vL}, \mathrm{M} / 2}=u_{\mathrm{vacL}, \mathrm{M} / 2}+U_{\mathrm{vdcL}, \mathrm{M} / 2} \\
U_{\mathrm{vacL}, M / 2}=\frac{1.05 U_{\mathrm{dcL}, M / 2}}{2} \\
U_{\mathrm{vdcL}, M / 2}=\frac{U_{\mathrm{dcL}, M / 2}}{2} \\
P_{\mathrm{MMCL}, M / 2}=\frac{\left(1-1 / k_{\mathrm{dc}}\right) P_{\mathrm{N}}}{M}
\end{gathered}
$$

where $u_{\mathrm{vL}, M / 2}$ is the voltage at $\mathrm{MMC}_{\mathrm{L}, \mathrm{M} / 2}$ valve side, $u_{\mathrm{vacL}, \mathrm{M} / 2}$ and $U_{\mathrm{vdcL}, \mathrm{M} / 2}$ are the AC component and DC component of $u_{\mathrm{vL}, M / 2} . U_{\mathrm{vacL}, M / 2}$ are the fundamental RMS L-L voltage at $\mathrm{MMC}_{\mathrm{L}, M / 2}$ valve side, $U_{\mathrm{dcL}, M / 2}$ is the $\mathrm{DC}$ voltage of $\mathrm{MMC}_{\mathrm{L}, M / 2} . P_{\mathrm{MMCL}, M / 2}$ is the power transmitted by $M M C_{\mathrm{L}, M / 2}$. Substituting these variables into (10), $C_{\mathrm{L}, M / 2}$ is described as:

$$
\begin{aligned}
C_{\mathrm{L}, M / 2} & =\frac{\sqrt{2}\left(1-1 / k_{\mathrm{dc}}\right) P_{\mathrm{N}} / M}{\sqrt{3} \times \frac{1.05}{2} U_{\mathrm{dcL}, M / 2} 2 \pi f C_{\mathrm{L}, M / 2}} \frac{1}{\frac{U_{\mathrm{dcL}, M / 2}}{2}} \\
& =0.496 \frac{\left(1-1 / k_{\mathrm{dc}}\right) P_{\mathrm{N}}}{M f \alpha_{\mathrm{L}, M / 2} U_{\mathrm{dcL}, M / 2}^{2}}
\end{aligned}
$$

where $\alpha_{\mathrm{L}, M / 2}$ is the fluctuation ratio of $u_{\mathrm{CL}, M / 2}$ of $C_{\mathrm{L}, M / 2}$. After specifying $\alpha_{\mathrm{L}, M / 2}$, the corresponding value of $C_{\mathrm{L}, M / 2}$ could be calculated by (22). The DC-isolation capacitor and the compensation inductor occur in series resonation at resonance frequency $f$ so that they produce no reactive power. Therefore, the calculation expression of $L_{\mathrm{L}, M / 2}$ is:

$$
L_{L, M / 2}=\frac{1}{(2 \pi f)^{2} C_{L, M / 2}}
$$


After obtaining the values of $C_{\mathrm{L}, M / 2}$ and $L_{\mathrm{L}, M / 2}$, the value of other DC-isolation capacitors in the LVM could be taken as the $C_{\mathrm{L}, M / 2}$, so that their $\alpha$ are smaller than $\alpha_{\mathrm{L}, M / 2}$ and $\alpha_{\mathrm{L},(M / 2)+1}$, as mentioned above. The values of other DC-isolation capacitors and compensation inductors in the LVM are described as:

$$
\left\{\begin{array}{l}
C_{\mathrm{L}, 1}=C_{\mathrm{L}, 2}=\cdots=C_{\mathrm{L}, M / 2}=\cdots=C_{\mathrm{L}, M} \\
L_{\mathrm{L}, 1}=L_{\mathrm{L}, 2}=\cdots=L_{\mathrm{L}, M / 2}=\cdots=L_{\mathrm{L}, M}
\end{array}\right.
$$

\section{Control Strategy of the MCAT}

\subsection{Dynamic Characteristics of the AC Side in the MCAT}

When neglecting the fluctuation of the voltage of the MMC sub-module capacitor, the internal AC fundamental equivalent circuit of the MCAT in the steady-state is shown in Figure 3 [19-21]. Here, $u_{\text {diffd } j}$ and $u_{\text {diffgj }}$ are the $d q$ axis components of the differential mode voltage $u_{\text {diffj }}$ output by $\mathrm{MMC}_{j}$ on the valve side [18], $i_{\mathrm{d} j}$ and $i_{\mathrm{q} j}$ are the $d q$ axis components of the current $I_{j}$ at $\mathrm{MMC}_{j}$ valve side, and $u_{\text {busd }}$ and $u_{\text {busq }}$ are the $d q$ axis components of $\mathrm{B}_{\text {com }}$ voltage $u_{\text {bus. }} L_{0}$ and $R_{0}$ are the $\mathrm{MMC}_{j}$ arm inductor and resistor respectively [22-25].

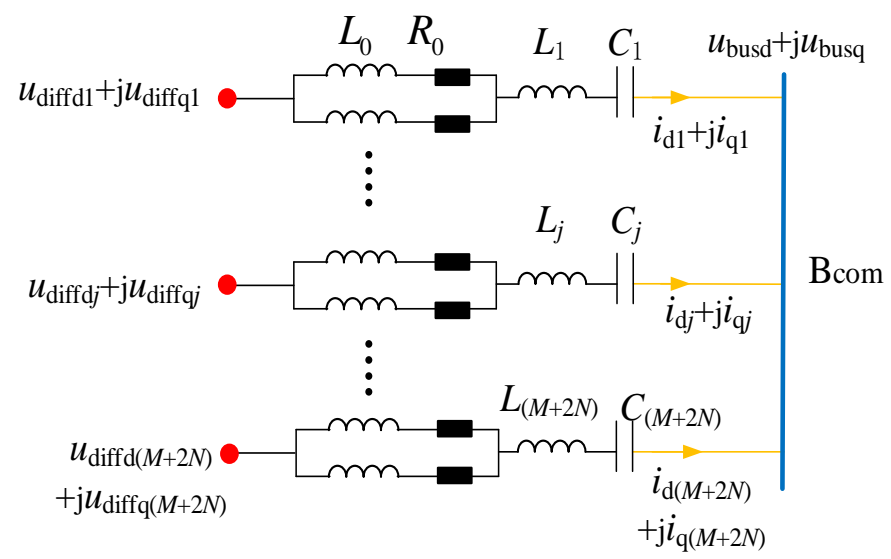

Figure 3. Equivalent circuit of the inner AC circuit of the MCAT.

$C_{j}$ and $L_{j}$ are series resonance in the fundamental circuit, and the circuit equation can be listed from Figure 3:

$$
\left\{\begin{array}{l}
u_{\text {diffd } j}=\left(R^{\prime}+L^{\prime} \frac{\mathrm{d}}{\mathrm{d} t}\right) i_{\mathrm{d} j}-\omega_{0} L^{\prime} i_{\mathrm{q} j}+u_{\mathrm{busd}} \\
u_{\text {diff } j}=\left(R^{\prime}+L^{\prime} \frac{\mathrm{d}}{\mathrm{d} t}\right) i_{\mathrm{q} j}+\omega_{0} L^{\prime} i_{\mathrm{d} j}+u_{\mathrm{busq}}
\end{array}\right.
$$

where $L^{\prime}=L_{0} / 2, R^{\prime}=R_{0} / 2$. Kirchhoff's current law (KCL) for $\mathrm{B}_{\mathrm{com}}$ is written as:

$$
\left\{\begin{array}{l}
\sum_{j=1}^{M+2 N} i_{\mathrm{d} j}=0 \\
\sum_{j=1}^{M+2 N} i_{\mathrm{q} j}=0
\end{array}\right.
$$

where $i_{\mathrm{d} j}$ and $i_{\mathrm{q} j}$ are obtained by Equation (25). Considering that $L^{\prime}$ is much larger than $R^{\prime}$ and substituting $i_{\mathrm{d} j}$ and $i_{\mathrm{q} j}$ into Equation (26), the following equation is obtained as:

$$
\left\{\begin{array}{l}
u_{\text {busd }}=\sum_{j=1}^{M+2 N} u_{\text {diffd } j} /(M+2 N) \\
u_{\text {busq }}=\sum_{j=1}^{M+2 N} u_{\text {diffq } j} /(M+2 N)
\end{array}\right.
$$

Equation (27) shows that the AC bus voltages $u_{\text {busd }}$ and $u_{\text {busq }}$ can be regulated by MMC. 


\subsection{MCAT Control Strategy in Normal Operation}

One typical scenario is that the high-voltage side of the MCAT is connected to the DC main grid which could be equivalent to a constant DC voltage source. The voltage of the low-voltage DC grid is required to be kept stable under control of the connected MCAT. In MCAT, the control of each MMC is independent and has the same inner loop control, while outer loop control strategy is different. The inner loop control has been introduced in [18], and this section focuses on the outer loop control. Different parts of MCAT adopt different outer loop control strategies. For this, the outer loop control strategy of the MCAT is discussed as follows.

The entire LVM is aimed to keep $E_{\text {low }}$ stability because of connecting with the lowvoltage DC grid directly, so they adopt DC voltage control as shown in Figure $4 \mathrm{a}$. $U_{\mathrm{dc}}$ and $Q_{S}$ are the DC voltage and reactive power at MMC ( $L V M$ and $M_{M} C_{H, N+1}$ to $\left.M_{M} C_{H, 2 N}\right)$ valve side, $U_{\mathrm{dc}}^{*}$ and $Q_{s}^{*}$ are the command references of $U_{\mathrm{dc}}$ and $Q_{\mathrm{s}} \cdot i_{\mathrm{dmax}}$ and $i_{\mathrm{qmax}}$ are used to limit $i_{\mathrm{d}}^{*}$ and $i_{\mathrm{q}}^{*}$.

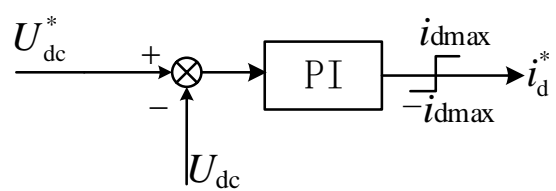

(a)
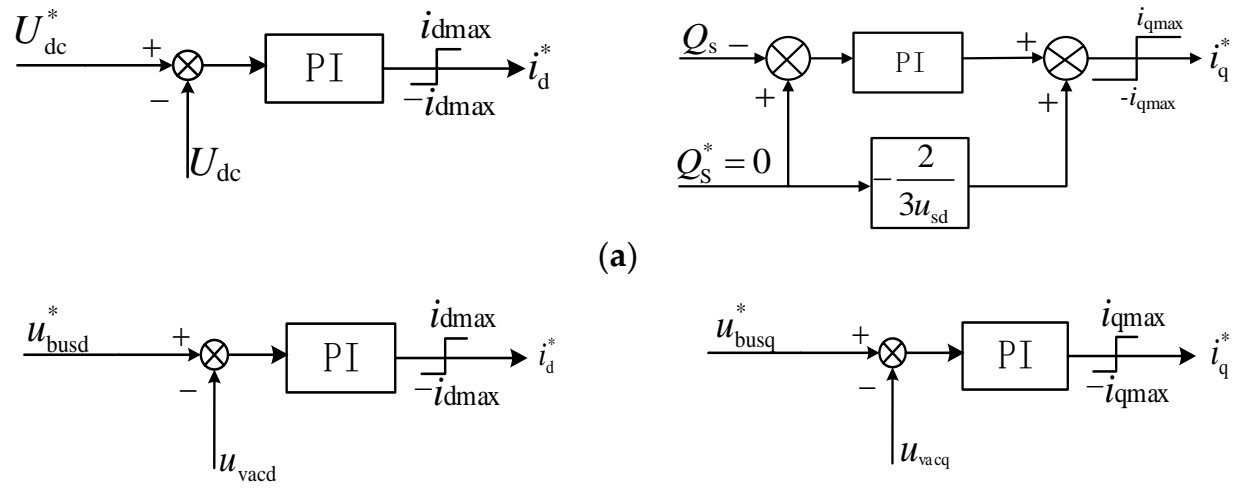

(b)

Figure 4. Schematic diagram of the MCAT outer loop control: (a) $\mathrm{MMC}_{\mathrm{H}, N+1}$ to $\mathrm{MMC}_{\mathrm{H}, 2 N}$ and LVM; (b) $\mathrm{MMC}_{\mathrm{H}, 1}$ to $\mathrm{MMC}_{\mathrm{H}, \mathrm{N}}$

$u_{\text {diffd }}$ and $u_{\text {diffq }}$ of MMCs are varied in response to the variation of the transmission power of the MCAT [16], which causes the AC bus voltage $u_{\text {bus }}$ fluctuations. Therefore, certain MMCs are supposed to not only control $u_{\text {bus }}$ but also serve as a power balance node $[26,27]$. $M M C_{H, 1}$ to $M M C_{H, N}$ (or $M M C_{H, N+1}$ to $M M C_{H, 2 N}$ ) in the HVM serve as the balance node and adopt passive control as shown in Figure $4 \mathrm{~b}[28-30] . u_{\mathrm{busd}}^{*}$ and $u_{\mathrm{busq}}^{*}$ are the command references of $u_{\text {busd }}$ and $u_{\text {busq. }} . U_{\text {vacd }}$ and $u_{\text {vacq }}$ are the $d q$ axis components of $U_{\mathrm{vac}}$.

Since $E_{\text {high }}$ and $E_{\text {low }}$ are controlled by the DC main grid and the LVM, respectively, $\mathrm{MMC}_{\mathrm{H}, \mathrm{N}+1}$ to $\mathrm{MMC}_{\mathrm{H}, 2 \mathrm{~N}}$ should adopt $\mathrm{DC}$ voltage control to keep voltages of passivecontrol MMCs stable.

The AC side control strategies of the $\mathrm{LVM}$ and $\mathrm{MMC}_{\mathrm{H}, \mathrm{N}+1}$ to $M \mathrm{MC}_{\mathrm{H}, 2 \mathrm{~N}}$ are aimed at reducing power losses, so they adopt reactive power control with reference value $0 \mathrm{pu}$ as shown in Figure 4a.

According to the above analysis, the AC and DC side control strategy in the MCAT normal operation is as shown in Table 1.

\subsection{MCAT AC-Side Short-Circuit Fault Recovery Strategy}

When an AC side short-circuit fault occurs at the internal AC bus of the MCAT, the voltage of the AC bus drops rapidly, causing the decrease of the power transmitted by $\mathrm{AC}$ bus and generating a large fault current. For this, MCAT are quickly blocked and AC circuit breakers are opened. After the transient fault is cleared, it is necessary to close the circuit breakers and unblock the MCAT to recover the power transmission. In order to maintain the voltages of DC-isolation capacitors stable, MMCs adopting passive control in 
the MCAT should be switched to DC voltage control with reference value $U_{\mathrm{dc}}^{*}$ and reactive power control with reference value $0 \mathrm{pu}$ when recovering, that is:

$$
U_{\mathrm{dc}}^{*}=\frac{\left(E_{\text {high }}-E_{\text {low }}\right)}{M}
$$

After the DC voltages of these MMCs are stabilized, they are switched to passive control again, and the system resumes steady-state operation.

Table 1. MCAT control strategy in normal operation.

\begin{tabular}{cc}
\hline Modules & Control Mode \\
\hline LVM & d-axis: DC voltage control \\
& q-axis: Reactive power control \\
& d-axis: DC voltage control \\
$M C_{\mathrm{H}, N+1}$ to $\mathrm{MMC}_{\mathrm{H}, 2 N}(\mathrm{HVM})$ & q-axis: Reactive power control \\
$\mathrm{MMC}_{\mathrm{H}, 1}$ to $\mathrm{MMC}_{\mathrm{H}, N}(\mathrm{HVM})$ & Passive control \\
\hline
\end{tabular}

\section{Simulation Study}

\subsection{Test System}

As shown in Figure 5, a 100 MW OWF with the MCAT is established in PSCAD/EMTDC. There are four clusters in this model, and each cluster is represented by a $25 \mathrm{MW}$ aggregated permanent magnets synchronous generators based on WTs (PMSG-WTs). The output DC voltage of the aggregated WT is $2.96 \mathrm{kV}$, and then requires two step-up DC-DC stages to reach the high voltage for DC transmission. The DC-DC converter in the WT boosts the DC voltage from $2.96 \mathrm{kV}$ to $100 \mathrm{kV}$ first, and then the MCAT steps up the DC voltage from $100 \mathrm{kV}$ to $300 \mathrm{kV}$. The internal DC-DC converters employ dual active bridge (DAB) topology. The parameters of equivalent PMSG and the DAB converters are listed in Table 2.

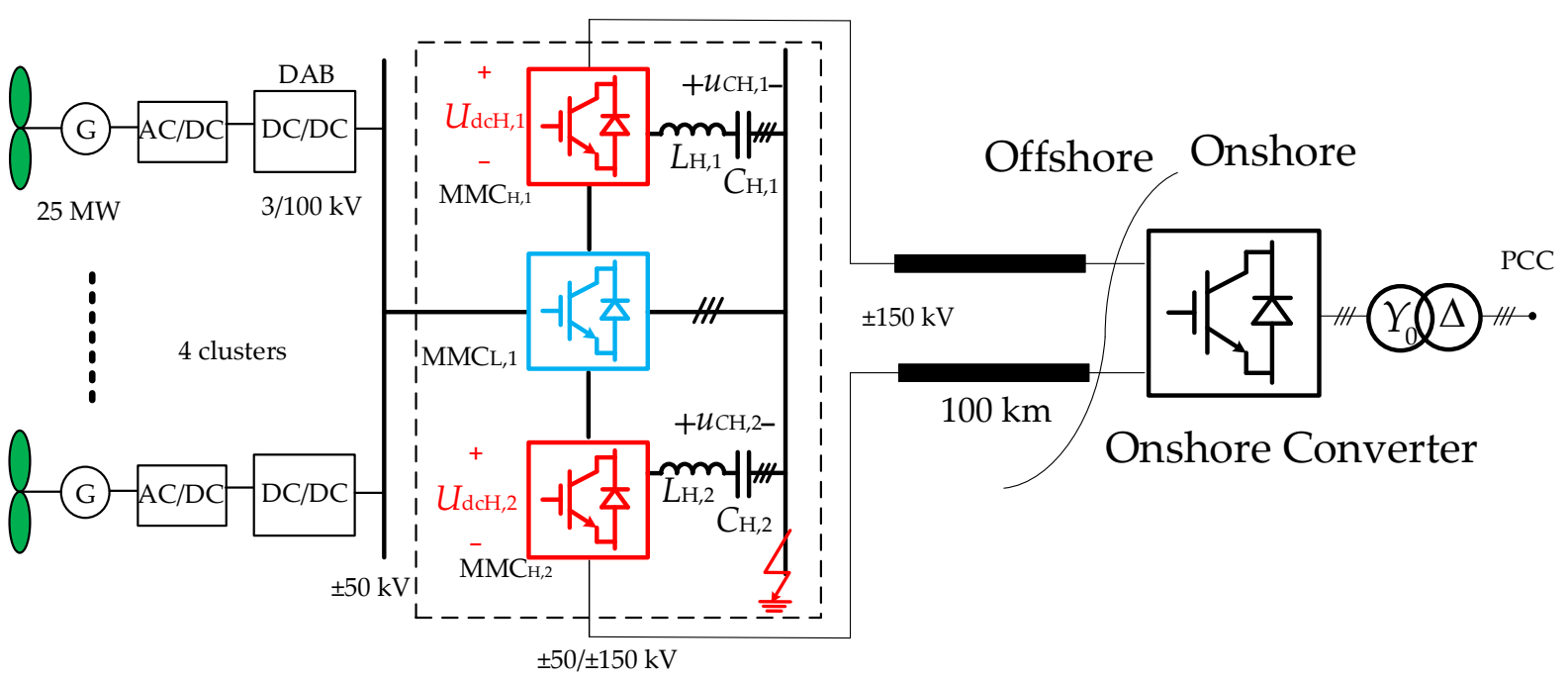

Figure 5. Diagram of the simulation system.

For the sake of simplicity, MCAT employs only three MMCs. When $\alpha_{\mathrm{H}, 1}$ is specified as $20 \%$, substitute $f=100 \mathrm{~Hz}, k_{\mathrm{dc}}=3, P=100 \mathrm{MW}, U_{\mathrm{dcH}, 1}=100 \mathrm{kV}$ and $N=1$ into Equations (9) and (10), then $C_{\mathrm{H}, 1}$ is calculated as $41.3 \mu \mathrm{F}$ and $L_{\mathrm{H}, 1}$ is $84.3 \mathrm{mH}$. $C_{\mathrm{L}, 1}$ and $L_{\mathrm{L}, 1}$ are excluded from the MCAT because of the symmetrical monopole construction. $\mathrm{C}_{\mathrm{H}, 2}$ and $L_{\mathrm{H}, 2}$ are equal to $41.3 \mu \mathrm{F}$ and $84.3 \mathrm{mH}$. The voltage rating across the MCAT is are $\pm 150 \mathrm{kV} / \pm 50 \mathrm{kV}$. Parameters of the MCAT, onshore converter, and HVDC cable are as shown in Tables 3 and 4. The control strategy of the MCAT is listed in Table 5. 
Table 2. Parameters of the aggregated WT.

\begin{tabular}{cccc}
\hline Item & Value & Item & Value \\
\hline Rated capacity/MVA & 25 & d-axis inductance $/ \mathrm{pu}$ & 0.41 \\
Rated voltage/kV & 2.96 & q-axis inductance $/ \mathrm{pu}$ & 0.77 \\
Frequency/Hz & 10 & Field flux/pu & 0.83 \\
Inertia constant/s & 2.5 & $\mathrm{DAB}$ converter rated capacity $/ \mathrm{MVA}$ & 28 \\
Stator resistance/pu & 0.1 & $\mathrm{DAB}$ converter rated input voltage $/ \mathrm{kV}$ & 2.96 \\
& & $\mathrm{DAB}$ converter rated output voltage $/ \mathrm{kV}$ & 100 \\
\hline
\end{tabular}

Table 3. Parameter in the MCAT.

\begin{tabular}{ccc}
\hline Item & $\mathbf{M M C}_{\mathbf{L}, \mathbf{1}}$ & $\mathbf{M M C}_{\mathbf{H , 1}} / \mathbf{M M C} \mathbf{C}_{\mathbf{H}, \mathbf{2}}$ \\
\hline Rated MMC capacity/MVA & 70 & 40 \\
Rated voltage $U_{\mathrm{dc}} / \mathrm{kV}$ & 100 & 100 \\
AC side frequency $/ \mathrm{Hz}$ & 100 & 100 \\
Rated submodule voltage $/ \mathrm{kV}$ & 2.0 & 2.0 \\
Number of submodules per arm & 50 & 50 \\
Submodule capacitance $/ \mu \mathrm{F}$ & 666 & 666 \\
Arm inductor $L_{0} / \mathrm{H}$ & 0.076 & 0.076 \\
$C_{\mathrm{H}, 1}, C_{\mathrm{H}, 2} / \mu \mathrm{F}$ & & 41.3 \\
$L_{\mathrm{H}, 1}, L_{\mathrm{H}, 2} / \mathrm{mH}$ & & 84.3 \\
\hline
\end{tabular}

Table 4. Parameters of the onshore converter and HVDC cable.

\begin{tabular}{|c|c|c|c|}
\hline Item & Value & Item & Value \\
\hline Rated MMC capacity/MVA & 200 & $\begin{array}{l}\text { Rated submodule } \\
\text { voltage } / \mathrm{kV}\end{array}$ & 2.0 \\
\hline Rated voltage $/ \mathrm{kV}$ & 300 & $\begin{array}{c}\text { Number of } \\
\text { submodules per arm }\end{array}$ & 150 \\
\hline Transformer rated power/MVA & 240 & $\begin{array}{c}\text { Submodule } \\
\text { capacitance } / \mu \mathrm{F}\end{array}$ & 666 \\
\hline Transformer radio & $220 / 157.5$ & Arm inductor $L_{0} / \mathrm{H}$ & 0.076 \\
\hline Transformer short-circuit inductance & 0.15 & Smoothing reactor $/ \mathrm{H}$ & 0.05 \\
\hline HVDC cable resistance $/ \Omega$ & 4.5 & $\begin{array}{c}\text { HVDC cable } \\
\text { inductance } / \mathrm{mH}\end{array}$ & 20 \\
\hline
\end{tabular}

Table 5. Control mode and reference value of the MCAT.

\begin{tabular}{ccc}
\hline Modules & Control Mode & Reference Value \\
\hline$M_{\mathrm{L}, 1}$ & d-axis: DC voltage control & $100 \mathrm{kV} ;$ \\
& q-axis: Reactive power control & $0 \mathrm{Mvar}$ \\
$\mathrm{MMC}_{\mathrm{H}, 2}$ & d-axis: DC voltage control & $100 \mathrm{kV} ;$ \\
$\mathrm{MMC}_{\mathrm{H}, 1}$ & q-axis: Reactive power control & $0 \mathrm{Mvar}$ \\
& Passive control & \\
\hline
\end{tabular}

\subsection{Simulation of Wind Speed Variation}

To validate the performance of the MCAT during wind speed variation, the transientstate process is designed as follows: at $t=1.0 \mathrm{~s}$, wind speed reduces from $12 \mathrm{~m} / \mathrm{s}$ to $8 \mathrm{~m} / \mathrm{s}$, and then maintains $8 \mathrm{~m} / \mathrm{s}$ for $2.5 \mathrm{~s}$, finally, rises to $10 \mathrm{~m} / \mathrm{s}$. Figure 5 shows the dynamic process of the test system.

Figure 6a illustrates that the transmission power of each MMC varies according to the wind speed quickly and stably. Figure $6 \mathrm{~b}, \mathrm{c}$ shows that the AC output current of each MMC and DC currents on both sides of the MCAT responds to the change of wind speed fast. Figure 6d,e shows the DC voltage of each MMC and DC voltages on both sides of MCAT, which are well balanced and stable. Figure $6 \mathrm{f}$ shows that the fluctuation of $u_{\mathrm{CH}, 1}$ and $u_{\mathrm{CH}, 2}$ is within $1.2 \mathrm{pu}$, proving the calculation of DC-isolation capacitors and compensation 
inductors are correct in Section 3. Figure $6 \mathrm{~g}$ demonstrates that the $\mathrm{AC}$ bus voltage are balanced well. Conclusively, the simulation results validate the feasibility of the proposed MCAT and the effectiveness of the control strategy.

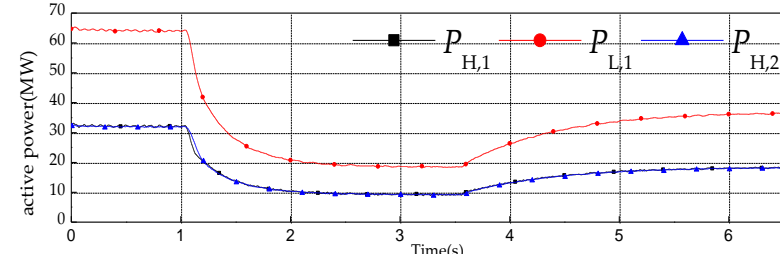

(a)

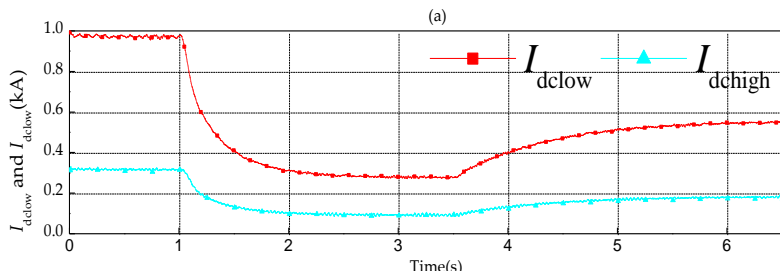

(c)

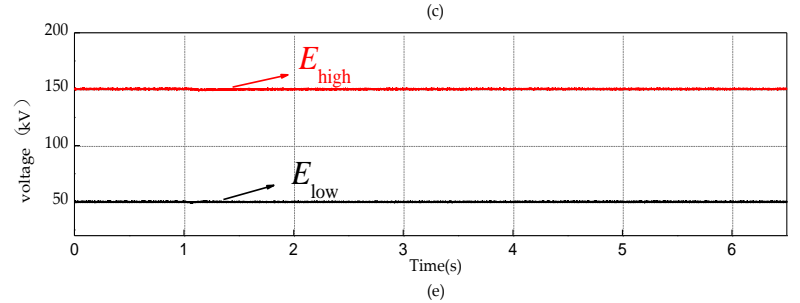

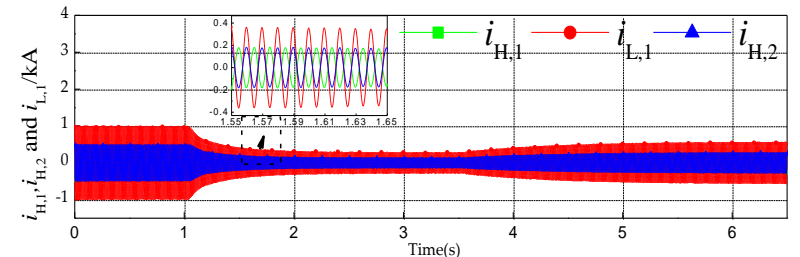

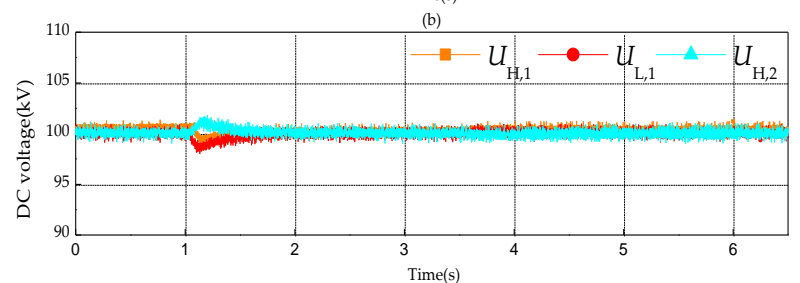

(d)

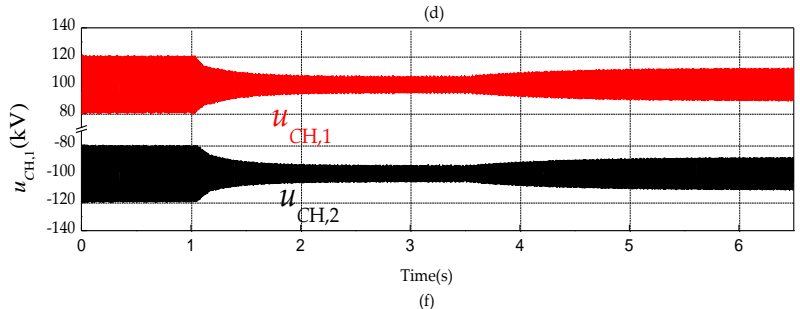

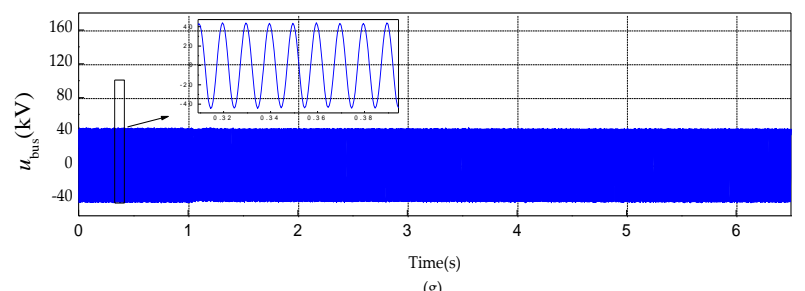

Figure 6. Simulation results of wind speed variation: (a) Active power transmitted by the MCAT; (b) A phase AC output current of MMCs; (c) DC currents of high-voltage and low-voltage DC grids respectively; (d) DC voltages of MMCs; (e) DC voltages of high-voltage and low-voltage DC grids respectively; (f) voltages of $C_{\mathrm{H}, 1}$ and $C_{\mathrm{H}, 2} ;(\mathrm{g})$ A phase $\mathrm{AC}$ voltage of the AC bus.

\subsection{Simulation of the Recovery Strategy}

At $t=0 \mathrm{~s}$, the test system is in steady-state. The sequences of the fault, applied control, and the protection measures are as follows:

(1) At $t=0.2 \mathrm{~s}$, the three-phase short circuit fault occurs at the AC bus, and the fault time lasts for $0.1 \mathrm{~s}$. At $t=0.202 \mathrm{~s}$, the MCAT, DAB converters inside WTs and onshore converters are blocked. An AC chopper facilitates the WT to consume the surplus energy and limits the DC overvoltage. At $t=0.206 \mathrm{~s}$, the fault current reduces to 0 due to the blocked MCAT.

(2) At $t=0.3 \mathrm{~s}$, the MCAT is unblocked, while the control strategy of $\mathrm{MMC}_{\mathrm{H}, 1}$ is switched from passive control to DC voltage control (reference value is $100 \mathrm{kV}$ ) and reactive power control (reference value is 0 MVar). At the same time, DAB converters inside WTs and onshore converters are unblocked. At $t=0.6 \mathrm{~s}, \mathrm{MMC}_{\mathrm{H}, 1}$ is switched to passive control again. Figure 6 shows the simulation diagram of fault response characteristics of the test system.

Figure 7a-e shows currents and voltages in the test system. When the three-phase short-circuit fault occurs at the AC bus, the maximum value of fault current reaches $0.75 \mathrm{kA}$ at about $0.201 \mathrm{~s}$, then the fault current is cut off rapidly. At $t=0.206 \mathrm{~s}$, blocking the MCAT make the DC current drop to 0 , but $U_{\mathrm{L}, 1}$ would reach $1.2 \mathrm{pu}$ because of the imbalance 
of power transmission. Since the AC bus is not grounded, its voltage is not dropped to 0 . At $t=0.40 \mathrm{~s}, I_{\text {dclow }}$ reaches 2 pu due to violent fluctuation of transmitted power. Therefore, the threshold value of overcurrent protection should be adjusted to prevent the MCAT from blocking again. At $t=0.8 \mathrm{~s}$, the currents and voltages in the test system are in steady-state again.
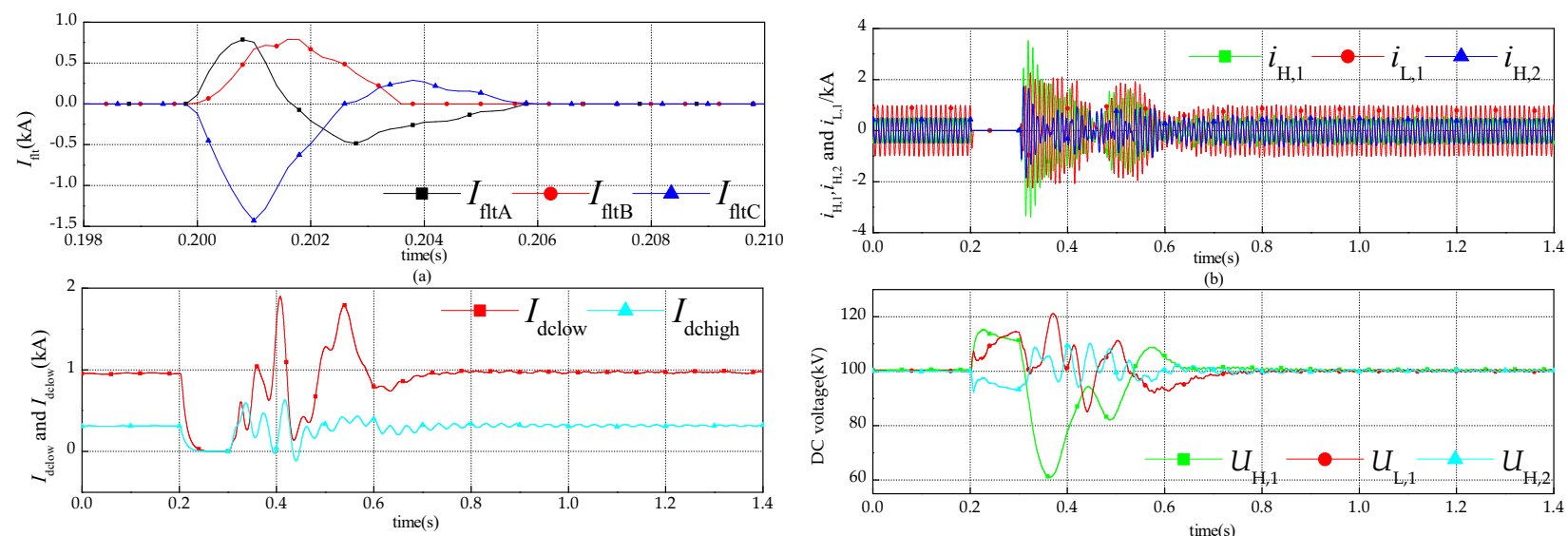

(c)
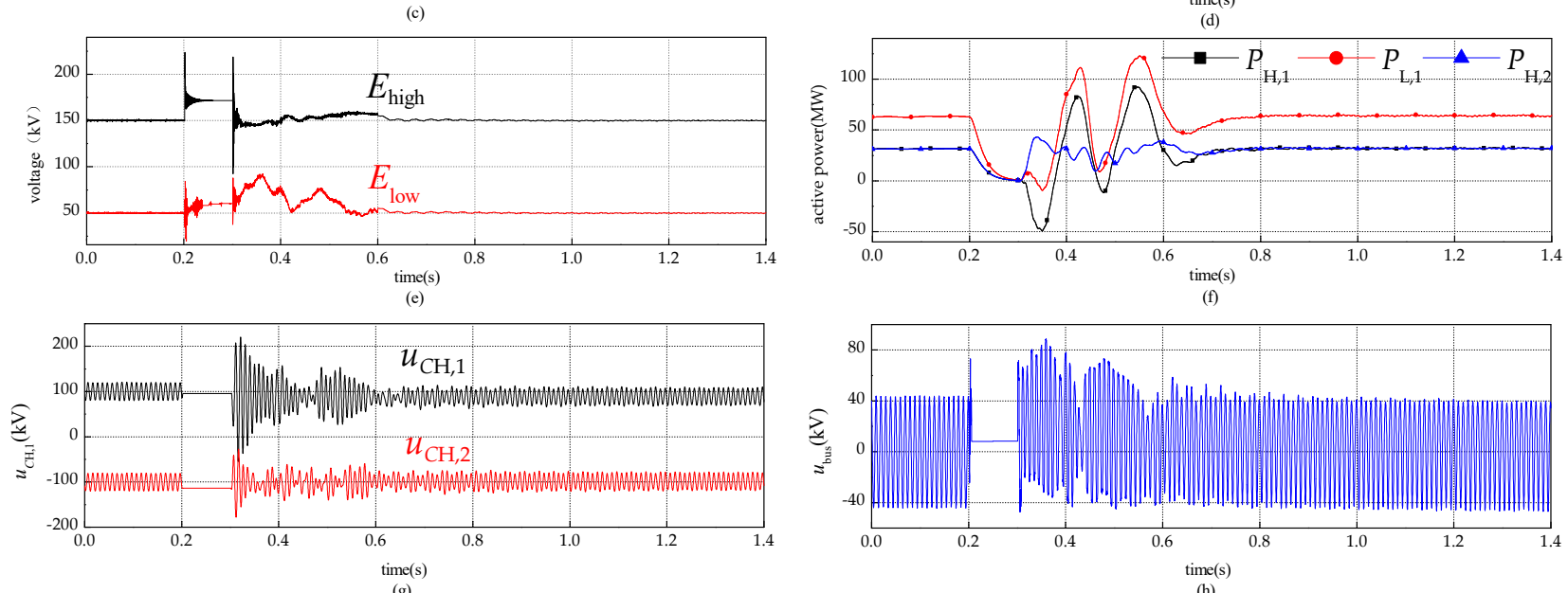

Figure 7. Simulation results of fault and recovery process: (a) Three-phase short circuit currents; (b) A phase AC output current of MMCs; (c) DC currents of high-voltage and low-voltage DC grids respectively; (d) DC voltages of MMCs; (e) DC voltages of high-voltage and low-voltage DC grids respectively; (f) active power transmitted by MMCs; (g) voltages of $C_{\mathrm{H}, 1}$ and $C_{\mathrm{H}, 2}$; (h) A phase voltage of the AC bus.

Figure $7 \mathrm{f}$, g shows the simulation results of $u_{\mathrm{CH}, 1}, u_{\mathrm{CH}, 2}$, and power changes of each MMC. At $t=0.3 \mathrm{~s}, C_{\mathrm{H}, 1}$ and $C_{\mathrm{H}, 2}$ have temporary overvoltage, and $u_{\mathrm{CH}, 1}$ reaches twice as the rated voltage. The transient process of capacitors voltages lasts for $0.4 \mathrm{~s}$. At $t=0.8 \mathrm{~s}$, the MCAT transmits rated power again.

Figure 7h shows the AC voltage of the AC bus could reach stable operation rapidly.

\section{Conclusions}

This paper presents the MCAT without the transformers. In the MCAT, the expensive converter transformers are substituted with the DC-isolation capacitor and compensation inductor in series to reduce the footprint of the offshore platforms. The selection methods of main circuit parameters for the MCAT are discussed in detail. Then, the control strategies of the MCAT are investigated under the steady-state operation and the AC fault recovery occurring at the AC bus. A detailed complicated OWF simulation model is constructed and the feasibility and effectiveness of the proposed MCAT and corresponding control strategies are validated. The conclusions are as follows: 
1. The proposed MCAT utilizes the DC-isolation capacitor to isolate the DC offset voltage of the converter transformers. The application of the compensation inductors facilitates improving the operation efficiency of the MCAT. The time-domain simulation results show that the calculation method of the main circuit parameters is correct, and the calculated values are highly consistent with the simulated values.

2. Ignoring the dynamic characteristics of MMC submodules, the output characteristics of the MCAT and the AC bus voltage could be regulated by MMCs adopting DC voltage control, reactive power control, and passive control strategies, respectively. The time-domain simulation proves that the voltage across the MCAT can remain stable under the condition of wind speed changes, and the output power can quickly respond to the wind speed changes. This indicates that the MCAT has favorable voltage control performance.

3. The fault recovery strategy proposed in this paper can help the MACT to quickly enter steady state. The test system is built in PSCAD/EMTDC, and the time-domain simulation shows that the MCAT could resume operation in a short time after the AC fault, which is conducive to maintaining the stable operation of the OWF.

Author Contributions: Conceptualization, Z.Z. and Z.X.; methodology, Z.X.; software, Z.Z.; validation, Y.S.; formal analysis, Y.S.; investigation, Y.S.; resources, Z.X.; data curation, Z.X.; writingoriginal draft preparation, Y.S.; writing-review and editing, Z.Z.; visualization, Z.Z.; supervision, Z.Z. and Z.X.; project administration, Z.X.; funding acquisition, Z.Z. and Z.X. All authors have read and agreed to the published version of the manuscript.

Funding: This research received no external funding.

Institutional Review Board Statement: Not applicable.

Informed Consent Statement: Not applicable.

Data Availability Statement: Data available on request due to privacy.

Conflicts of Interest: The authors declare no conflict of interest.

\section{Appendix A}

Table A1. Explanations of the abbreviations and symbols used in this section.

\begin{tabular}{|c|c|c|c|}
\hline Symbols & Explanations of Symbols & Symbols & Explanations of Symbols \\
\hline$u_{\mathrm{c} j}$ & \multirow{11}{*}{$\begin{array}{c}\text { the voltage of } C_{j} \\
\text { DC component of } u_{\mathrm{c} j} \\
\text { AC component of } u_{\mathrm{c} j} \\
\text { fundamental RMS L-L voltage at } \mathrm{MMC}_{j} \\
\text { valve side } \\
\text { fundamental RMS line current at } \mathrm{MMC}_{j} \\
\text { valve side } \\
\text { the phase angle between } U_{\mathrm{vacj}} \text { and } I_{j} \\
\text { fundamental RMS voltage of } \Delta u_{\mathrm{c} j} \\
\text { fundamental frequency at the MCAT AC side } \\
\text { fluctuation ratio of } u_{\mathrm{c} j} \\
\text { fluctuation ratio of } u_{\mathrm{CH}, N} \\
\text { fluctuation ratio of } u_{\mathrm{CL}, M / 2}\end{array}$} & $u_{\mathrm{vacL}, M / 2}$ & AC component of $u_{\mathrm{vL}, M / 2}$ \\
\hline$U_{\mathrm{vdc} j}$ & & $U_{\mathrm{vdcH}, N}$ & DC component of $u_{\mathrm{vH}, N}$ \\
\hline$\Delta u_{\mathrm{c} j}$ & & $U_{\mathrm{vdcL}, M / 2}$ & DC component of $u_{\mathrm{vL}, M / 2}$ \\
\hline$U_{\text {vacj }}$ & & $U_{\mathrm{vacH}, N}$ & Fundamental component of $u_{\mathrm{vacH}, \mathrm{N}}$ \\
\hline$I_{j}$ & & $U_{\mathrm{vacL}, M / 2}$ & Fundamental component of $u_{\mathrm{vacL}, M / 2}$ \\
\hline$\delta_{j}$ & & $U_{\mathrm{dcH}, N}$ & DC voltage of $\mathrm{MMC}_{\mathrm{H}, \mathrm{N}}$ \\
\hline$\Delta U_{\mathrm{cj}}$ & & $U_{\mathrm{dcL}, M / 2}$ & $\mathrm{DC}$ voltage of $\mathrm{MMC}_{\mathrm{L}, M / 2}$ \\
\hline$f$ & & $u_{\mathrm{vH}, N}$ & the voltage at $\mathrm{MMC}_{\mathrm{H}, N}$ valve side \\
\hline$\alpha_{j}$ & & $u_{\mathrm{vL}, M / 2}$ & the voltage at $M M C_{L, M / 2}$ valve side \\
\hline$\alpha_{\mathrm{H}, N}$ & & $u_{\mathrm{vacH}, N}$ & AC component of $u_{\mathrm{vH}, N}$ \\
\hline$\alpha_{\mathrm{L}, M / 2}$ & & & \\
\hline
\end{tabular}

\section{References}

1. Wang, Q.; Yu, Z.; Ye, R.; Lin, Z.; Tang, Y. An ordered curtailment strategy for offshore wind power under extreme weather conditions considering the resilience of the grid. IEEE Access 2019, 7, 54824-54833. [CrossRef]

2. Bresesti, P.; Kling, W.L.; Hendriks, R.L.; Vailati, R. HVDC connection of offshore wind farms to the transmission system. IEEE Trans. Energy Convers. 2007, 22, 37-43. [CrossRef]

3. Elliott, D.; Bell, K.R.W.; Finney, S.J.; Adapa, R.; Brozio, C.; Yu, J.; Hussain, K. A comparison of AC and HVDC options for the connection of offshore wind generation in Great Britain. IEEE Trans. Power 2016, 31, 798-809. [CrossRef] 
4. $\quad$ Engel, S.P.; Stieneker, M.; Soltau, N.; Rabiee, S.; Stagge, H.; de Doncker, R.W. Comparison of the modular multilevel DC converter and the dual-active bridge converter for power conversion in HVDC and MVDC grids. IEEE Trans. Power Electron. 2015, 30, 124-137. [CrossRef]

5. Lumbreras, S.; Ramos, A. Offshore wind farm electrical design: A review. Wind Energy 2013, 16, 459-473. [CrossRef]

6. Taherbaneh, M.; Jovcic, D.; Taisne, J.P.; Nguefeu, S. DC fault performance and cost analysis of dc grids for connecting multiple offshore wind farms. In Proceedings of the 2013 IEEE Grenoble PowerTech (POWERTECH), Grenoble, France, 16-20 June 2013.

7. Deng, F.; Chen, Z. Operation and control of a DC-grid offshore wind farm under DC transmission system faults. IEEE Trans. Power Deliv. 2013, 28, 1356-1363. [CrossRef]

8. Robinson, J.; Jovcic, D.; Joos, G. Analysis and design of an offshore wind farm using a MV DC grid. IEEE Trans. Power Del. 2010, 25, 2164-2173. [CrossRef]

9. Lian, Y.; Adam, G.; Holliday, D.; Finney, S. Medium-voltage DC/DC converter for offshore wind collection grid. IET Renew. Power Gener. 2016, 5, 651-660. [CrossRef]

10. Hu, P.; Yin, R.; Wei, B.; Luo, Y.; Blaabjerg, F. Modular Isolated LLC DC/DC Conversion System for Offshore Wind Farm Collection and Integration. IEEE J. Emerg. Sel. Top. Power Electron. 2021, 9, 6713-6725. [CrossRef]

11. Hu, P.; Yin, R.; He, Z.; Wang, C. A Modular Multiple DC Transformer Based DC Transmission System for PMSG Based Offshore Wind Farm Integration. IEEE Access 2020, 8, 15736-15746. [CrossRef]

12. Páez, J.D.; Frey, D.; Maneiro, J.; Bacha, S.; Dworakowski, P. Overview of DC-DC Converters Dedicated to HVDC Grids. IEEE Trans. Power Deliv. 2019, 34, 119-128.

13. Parastar, A.; Kang, Y.C.; Seok, J.-K. Multilevel modular DC/DC power converter for high-voltage DC-connected offshore wind energy applications. IEEE Trans. Ind. Electron. 2015, 5, 2879-2890. [CrossRef]

14. Lin, W. DC-DC autotransformer with bidirectional DC fault isolating capability. IEEE Trans. Power Electron. 2015, 31, 5400-5410. [CrossRef]

15. Li, X.Y.; Zhu, M.; Su, M.; Ma, J.; Li, Y.R.; Cai, X. Input-independent and output-series connected modular DC-DC converter with intermodule power balancing units for MVdc Integration of distributed PV. IEEE Trans. Power Electron. 2020, 35, $1622-1636$. [CrossRef]

16. Chen, Y.; Wang, H.; Zhu, M.; Liu, M.; Cai, X. Modular DC-DC auto-transformer: Topology, operation, and system design. IET Power Electron. 2021, 14, 2289-2302. [CrossRef]

17. Xu, Z.; Tu, Q.; Guan, M. Voltage Source Converter Based HVDC Power Transmission Systems, 2nd ed.; China Machine Press: Beijing, China, 2013

18. Xu, Z. Voltage Source Converter Based HVDC Power Transmission Systems, 2nd ed.; China Machine Press: Beijing, China, 2016.

19. Xu, Z.; Xiao, H.; Zhang, Z. Selection methods of main circuit parameters for modular multilevel converters. IET Renew. Power Gener. 2016, 10, 788-797. [CrossRef]

20. Sun, C.; Zhang, J.; Cai, X.; Shi, G. Voltage balancing control of isolated modular multilevel dc-dc converter for use in dc grids with zero voltage switching. IET Power Electron. 2016, 9, 270-280. [CrossRef]

21. Tu, Q.; Xu, Z.; Xu, L. Reduced switching-frequency modulation and circulation current suppression for modular multilevel converters. IEEE Trans. Power Deliv. 2011, 26, 2009-2017.

22. Xiang, W.; Lin, W.; Xu, L.; Wen, J. Enhanced Independent Pole Control of Hybrid MMC-HVDC System. IEEE Trans. Power Deliv. 2018, 33, 861-872. [CrossRef]

23. Yao, W.; Jiang, L.; Wen, J.; Wu, Q.; Cheng, S. Wide-Area Damping Controller for Power System Interarea Oscillations: A Networked Predictive Control Approach. IEEE Trans. Control Syst. Technol. 2015, 23, 27-36. [CrossRef]

24. Luth, T.; Merlin, M.M.C.; Green, T.C.; Hassan, F.; Barker, C.D. High-frequency operation of a DC/AC/DC system for HVDC applications. IEEE Trans. Power Electron. 2014, 29, 4107-4115. [CrossRef]

25. Wu, Y.; Lu, Z.; He, Z. Study on the protection strategies of HVDC grid for overhead line application. CSEE 2016, 36, 3726-3734.

26. Li, X.; Xu, Z.; Zhang, Z. Enhanced Ride-Through Capability Under Rectifier-Side AC Fault for Series LCC-MMC Hybrid HVDC System. IEEE Access 2021, 9, 153050-153057. [CrossRef]

27. Suo, Z.; Li, G.; Xu, L.; Li, R.; Wang, W.; Chi, Y. Hybrid modular multilevel converter based multi-terminal DC/DC converter with minimized full-bridge submodules ratio considering DC fault isolation. IET Renew. Power Gener. 2016, 10, 1587-1596. [CrossRef]

28. Ruddy, J.; Meere, R.; O'Donnell, T. A Comparison of VSC-HVDC with Low Frequency AC for Offshore Wind Farm Design and Interconnection. Energy Procedia 2015, 80, 185-192. [CrossRef]

29. Yu, F.; Lin, W.; Wang, X.; Xie, D. Fast voltage-balancing control and fast numerical simulation model for the modular multilevel converter. IEEE Trans. Power Deliv. 2015, 30, 220-228. [CrossRef]

30. Zhao, W. HVDC Engineering Technology, 2nd ed.; China Electric Power Press: Beijing, China, 2011. 